\title{
Risk factors associated with anorectal malformations development
}

\author{
A case-control study
}

Mohammed A. Almatrafi, MBBS, SBPM, Abdulmohsen H. Al-Zalabani, MSc(epi), ABCM, Hamdi H. Almaramhy, FRCS, SBPS, Sami A. Al-Dubai, MPH, PhD.

\section{ABSTRACT}

$$
\begin{aligned}
& \text { الأهداف : لتحديد عو امل الخطر لتطوير التشوهات الشرجية (ARM ). }
\end{aligned}
$$

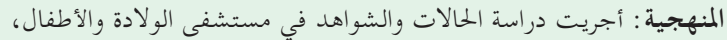

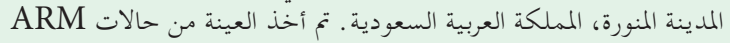

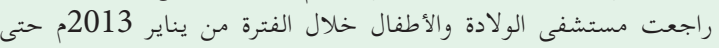

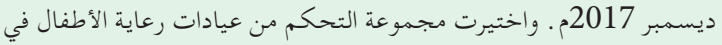

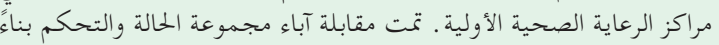

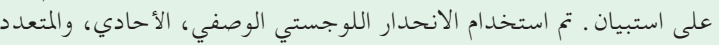

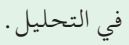

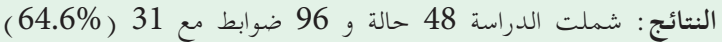

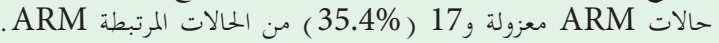

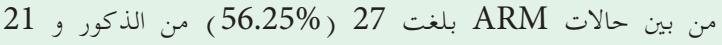

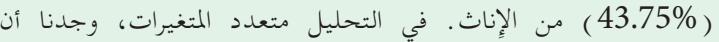

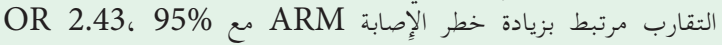

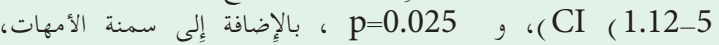

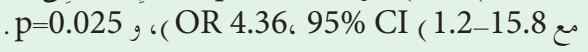

$$
\begin{aligned}
& \text { الخلاصة : وجدنا القرابة وسمنة الأمهات ( BMI } 30 \text { (BMI ) عوامل خطر لتطور } \\
& \text { التشوهات الشرجية وجداصنا لقرابة وسمنة. }
\end{aligned}
$$

Objectives: To determine the risk factors for the development of anorectal malformations (ARM).

Methods: This case-control study was conducted in the Maternity and Children Hospital (MCH), Al Madinah Al Munnawarah, Saudi Arabia. The sample was taken from the ARM cases admitted at $\mathrm{MCH}$ between January 2013 and December 2017. The controls were selected from well-baby clinics in primary health care centers. Parents of the cases and the controls were interviewed based on a questionnaire. Descriptive, univariate, and multivariate logistic regression were used in the analysis.

Results: The study included 48 cases and 96 controls with 31 (64.6\%) cases of isolated ARM and 17 (35.4\%) cases of associated ARM. Among the ARM cases, 27 $(56.3 \%)$ were males and $21(43.8 \%)$ were females. In multivariate analysis, we found consanguinity to be associated with an increased risk of developing ARM with odds ratio (OR): $2.43,95 \%$ CI: $1.12-5$, and $p=0.025$, in addition to maternal obesity, with OR: $4.36,95 \%$ CI: $1.2-15.8$, and $p=0.025$.

Conclusion: Consanguinity and maternal obesity (body mass index $>30$ ) were found to be risk factors for ARM development.

Keywords: anorectal malformations, risk factors, consanguinity, maternal obesity, case-control study

Saudi Med J 2020; Vol. 41 (2): 157-162 doi: 10.15537/smj.2020.2.24882

From the Saudi Board of Preventive Medicine (Almatrafi, Al-Dubai); from the Family and Community Medicine Department (Al-Zalabani), College of Medicine; and from the Pediatric Surgery Department (Almaramhy), College of Medicine, Taibah University, Al Madinah Al Munnawarah, Kingdom of Saudi Arabia.

Received 31st July 2019. Accepted 26th December 2019.

Address correspondence and reprint request to: Dr. Hamdi $H$. Almaramhy, Pediatric Surgery Department, College of Medicine, Taibah University, Al Madinah Al Munnawarah, Kingdom of Saudi Arabia.E-mail; hmaramhy@taibahu.edu.sa

ORCID ID: https://orcid.org/0000-0003-2080-122X

A norectal malformations (ARM) are congenital disorders that affect nearly $1 / 2000$ to $1 / 5000$ newborns. ${ }^{1}$ The incidence in Al-Madinah Al Munnawarah, Saudi Arabia is estimated to be $1 / 1000$, which is higher than the incidence reported in many countries. ${ }^{2}$ Anorectal malformation encompass a spectrum of anomalies that affect the lower part of the gastrointestinal and genitourinary systems and present 
in different phenotypes. One of the simplest as well as popular classification is the Krickenbeck classification, wherein males were classified as perineal fistula, rectourethral bulbar fistula, rectourethral prostatic fistula, and rectovesical fistula. While in females, they were classified as perineal fistula, vestibular fistula, and cloacal lesions. ${ }^{3}$ Anorectal malformations may be present as an isolated anomaly or associated with others.

The exact etiology for ARM is unknown; however, there are previous studies claiming that both genetic and non-genetic factors play a role. Among the non-genetic factors that have been studied are the maternal and paternal factors. Many maternal risk factors have been investigated, including diabetes, obesity, fever during pregnancy, exposure to smoking during pregnancy, exposure to household smoke, and the use of anti-asthma and hypnotic medications as well as benzodiazepines during pregnancy. 4,5 Gestational diabetes has a high prevalence in Al-Madinah $\mathrm{Al}$ Munnawarah and it is one of the factors that need more evidence to assess their relation to ARM. ${ }^{6,7}$ With regard to paternal factors, cigarette and water pipe smoking were the main concerns. Water pipe smoking is highly prevalent in eastern communities, and there have been concerns about its effect on pregnancy outcomes, as it is associated with the same toxins as cigarette smoking and its effect may be augmented in presence of pregestational diabetes. ${ }^{8}$ Nevertheless, only a few factors were consistently found to be associated with ARMs, notably multiple pregnancy, preterm delivery, low birth weight, maternal overweight, obesity, and pre-existing diabetes. ${ }^{4}$ Family history seems to have a contribution in ARM etiology. ${ }^{9}$

The aim of this study is to determine the maternal and paternal risk factors for the development of ARM.

Methods. This study was conducted in the Maternity and Children Hospital $(\mathrm{MCH})$ and primary healthcare centers in Al-Madinah Al Munnawarah, Saudi Arabia. The $\mathrm{MCH}$ is the only government hospital that offers pediatric surgery in Al-Madinah Al Munnawarah, region.

The case-control study design was used in the current study. We included all patients admitted at $\mathrm{MCH}$ in Al-Madinah Al Munnawarah between 2013 and 2017, diagnosed with isolated ARM or ARM associated

Disclosure. Authors have no conflict of interests, and the work was not supported or funded by any drug company. with other anomalies (non-syndromic), whose parents could be contacted. Controls were defined as children under 5 years of age, without congenital anomalies, who attended the well-baby clinics in the primary health centers in Al-Madinah region. We excluded all cases that have not met the above-mentioned criteria. Controls were also excluded if they were diagnosed to have other congenital anomalies.

The required sample size was calculated by using the Kelsey equation through OpenEpi. ${ }^{10}$ The desired study power was $80 \%$ at 95 confidence interval (CI), with $51 \%$ prevalence of exposure among controls and the odds ratio (OR) was 3, and the case to control ratio was 1:2.4,6,11 The required sample size was 47 cases and 93 controls.

All ARM cases admitted at MCH, who met the inclusion criteria, were included. The controls, on the other hand, were selected and interviewed from the well-baby clinics in 5 primary health centers within the Al-Madinah Al Munnawarah region. The primary health centers were selected from different geographical areas, where 4 centers were within Al-Madinah $\mathrm{Al}$ Munnawarah city and one center was in a rural area. In each center, the data collection was undertaken by trained staff, mainly one physician and one to 2 assistant nurses. The case to control ratio was 1:2, matched for the age and gender of the children.

A questionnaire was developed in Arabic, based on the literature review and the Genetic, Occupational and Environmental risk factors for Anomalies in children (AGORA) and Pregnancy Risk Assessment Monitoring System (PRAMS) questionnaires. The questions obtained from the validated AGORA questionnaire were in 2 parts, addressed to the mother and the father, and were developed by Radboud University Nijmegen Medical Centre, the Netherlands, questions about cigarette smoking were modified from the validated PRAMS questionnaire, which was structured by the Centers for Disease Control and Prevention (CDC). ${ }^{12,13}$

The first section of the questionnaire was related to the demographic data of the mother, father, and child, such as age (of child/parents), gender, and nationality. The other section contained detailed questions about certain risk factors, such as multiple pregnancy, preterm delivery, low birth weight, maternal weight and height (BMI), gestational diabetes, pre-existing diabetes, and maternal intake of contraceptive pills, folic acid, iron supplements, antibiotics, and medication for psychiatric illness, in addition to exposure to household smoke and parental smoking (either cigarette or water pipe).

To ensure the validity of the questionnaire, a face validity was performed by one of the researcher from 
the same specialty, the Department of Pediatrics (pediatric surgery) in the $\mathrm{MCH}$ hospital. The second researcher was from the Department of Community Medicine and was concerned with the technical validity of the questionnaire. Furthermore, the questionnaire's clarity and understandability to parents was tested on a number of parents at the pediatric surgery clinic in the $\mathrm{MCH}$ hospital before starting the study.

Operational definition of outcome and independent variables. Anorectal malformations were defined as the absence of an anus or an abnormal anus, with or without a fistula, and they were classified according to the Krickenbeck criteria. ${ }^{3}$ The diagnosis was confirmed by the clinical findings as well as the images of lateral cross-table radiography and the distal colostography with a created colostomy. In addition, echocardiogram, abdominal ultrasound, and spine radiography findings were also analyzed. The cases were categorized as follows: isolated ARM and associated ARM. ${ }^{2}$

Independent variables were defined as follows: 1) gestational diabetes as diabetes mellitus arising in the pregnancy; 2) current smoker, who has smoked 100 cigarettes in his or her lifetime and who currently smokes cigarettes; 3 ) water pipe smoking was defined as smoking water pipe at least once a month: 4) multiple pregnancy as woman has 2 or more babies in her uterus; 5) preterm delivery as delivered in less than 37 weeks of gestation; and 6) low birth weight, birth weight less than 2500 grams. ${ }^{14-16}$

The medical records were reviewed to enumerate the ARM cases documented between 2013 and 2017. The following information was then extracted from the charts: patient characteristics, type of anomaly, associated anomalies, and contact information of the parents. Trained physicians then conducted either a direct interview or a telephonic interview.

The direct interview/phone interview centered around the questionnaire and information was obtained from both the parents, when available.

Statistical analysis. Data analyses were carried out using the Statistical Package for Social Sciences for Windows, version 20 (IBM Corp, Armonk, NY, USA). Descriptive (categorical and continuous variables), univariate (Chi-square), and multivariate analysis (multiple logistic regression) were used to assess the selected risk factors for ARM. Fisher's exact test was used when the assumption was not met in the Chi-square test for association. The significance level was considered as $p<0.05$.

Ethical approval was obtained from the ethics committee of the General Directory in the Ministry of Health and Maternity and Children Hospital,
Al-Madinah Al Munnawarah, Saudi Arabia. Informed consent was obtained from participating parents, including an explanation of the study and the right of withdrawing from the study without any responsibility.

Results. Following the reviewing of records, 83 cases were included in the study. Cases that were excluded were as follows: those with known chromosomal abnormalities $(n=11)$, cases with missing contact information $(n=14)$, and non-respondents $(n=10)$. Finally, 48 cases and 96 controls were included in the study. The number of isolated ARM was 31 (64.6\%), whereas the number of associated ARM cases was 17 (35.4\%). Among the ARM cases, 56.3\% were males and 43.8 were females. The types of ARM were as follows: perineal fistula (4.2\%), anterior displaced anus $(25 \%)$, rectal atresia with urethral fistula (41.7\%) rectal atresia (10.4\%), vestibular anus (16.6\%), and cloacal malformations (2.1\%) (Table 1$)$. On the other hand, among the controls, there were 54 males and 42 females. The distributions of descriptive characteristics of the risk factors for cases and controls are shown in Table 2. The following results were obtained in the univariate analysis (Table 2): Nationality $(p=0.010)$; consanguinity (1st degree) $(p=0.012)$; body mass index (BMI) underweight $(p=0.026)$ and BMI obese $(p=0.002)$; gestational age, premature $(p=0.028)$; and folic acid supplementation during pregnancy $(p=0.097)$.

All variables associated significantly with ARM in univariate analysis were entered into the multivariate

Table 1 - Anorectal malformation types, isolated ARM and associated ARM,among males and females

\begin{tabular}{|c|c|c|c|}
\hline & $\begin{array}{l}\text { Males } \\
\text { n (\%) }\end{array}$ & $\begin{array}{c}\text { Females } \\
\text { n (\%) }\end{array}$ & $\begin{array}{l}\text { Total } \\
\text { n (\%) }\end{array}$ \\
\hline All ARM & $27(56.3)$ & $21(43.7)$ & \\
\hline \multicolumn{4}{|l|}{ ARM types } \\
\hline Perineal fistula & $2(7.4)$ & 0 & $2(4.2)$ \\
\hline $\begin{array}{l}\text { Anterior displaced } \\
\text { anus }\end{array}$ & $1 \quad(3.7)$ & $11(52.4)$ & $12(25.0)$ \\
\hline $\begin{array}{l}\text { Recto-urethral } \\
\text { fistula }\end{array}$ & $20(74.0)$ & 0 & $20(41.7)$ \\
\hline Rectal atresia & $4(14.8)$ & $1 \quad(4.8)$ & $5(10.4)$ \\
\hline Vestibular anus & 0 & $8 \quad(38)$ & $8(16.6)$ \\
\hline $\begin{array}{l}\text { Cloacal } \\
\text { malformations }\end{array}$ & 0 & $1 \quad(4.8)$ & $1 \quad(2.1)$ \\
\hline Isolated ARM & $16(59.3)$ & $15(71.4)$ & $31(64.6)$ \\
\hline Associated anomalies & $11(40.7)$ & $6(28.7)$ & $17(35.4)$ \\
\hline Vertebral & 1 & 2 & \\
\hline Cardiac & 8 & 2 & \\
\hline Renal & 4 & 2 & \\
\hline Limb defects & 1 & 2 & \\
\hline Orofacial & 1 & 0 & \\
\hline
\end{tabular}


analysis (BMI, gestational age, nationality and consanguinity [1st degree relative]). Prematurity was found statistically insignificant. However, cases with consanguinity were found to have a higher risk of developing ARM compared to that in the controls $(p=0.025)$; obese mothers showed a higher risk of developing ARM with $(p=0.025)$. Children of non-Saudi parents when compared to those of Saudi parents, showed a risk of developing ARM $(p=0.034)$ (Table 3).

Table 2 - Factors associated with anorectal malformations (ARM) development in univariate analysis.

\begin{tabular}{|c|c|c|c|c|c|}
\hline Factors & Cases & Controls & OR & $\begin{array}{c}95 \% \\
\text { confidence } \\
\text { interval }\end{array}$ & $P$-value \\
\hline \multicolumn{6}{|c|}{ Maternal education level } \\
\hline Primary & $11(22.9)$ & $25(26.0)$ & Ref & & \\
\hline Secondary & $7(14.6)$ & $31(32.3)$ & 0.5 & $(0.2-1.5)$ & 0.228 \\
\hline University & $30(62.5)$ & $40(41.7)$ & 1.7 & $(0.7-3.9)$ & 0.220 \\
\hline \multicolumn{6}{|l|}{ Nationality } \\
\hline Non-Saudi & $9(69.2)$ & $4(30.8)$ & 5.3 & $(1.5-18.3)$ & 0.010 \\
\hline Saudi & $39(29.8)$ & $92(70.2)$ & & & \\
\hline \multicolumn{6}{|l|}{ Consanguinity } \\
\hline Yes & $27(56.3)$ & $33(34.4)$ & 2.4 & $(1.2-4.9)$ & 0.012 \\
\hline No & $21(43.8)$ & $63(65.6)$ & & & \\
\hline \multicolumn{6}{|c|}{ Family history of ARM } \\
\hline Yes & $6(12.5)$ & 0 & 3.3 & $(2.5-4.2)$ & 0.001 \\
\hline No & $42(87.5)$ & $96(100)$ & & & \\
\hline \multicolumn{6}{|l|}{ Parity } \\
\hline Null parity & $13(27.1)$ & $28(29.2)$ & 0.9 & $(0.4-1.9)$ & 0.794 \\
\hline Multi parity & $35(72.9)$ & $68(70.8)$ & & & \\
\hline \multicolumn{6}{|l|}{ Maternal BMI } \\
\hline Normal & $16(33.3)$ & $52(54.2)$ & Ref & & \\
\hline Underweight & $4 \quad(8.3)$ & $1 \quad(1.0)$ & 13 & $(1.3-124)$ & 0.026 \\
\hline Overweight & $18(37.5)$ & $38(39.6)$ & 1.5 & $(0.7-3.4)$ & 0.286 \\
\hline Obese & $10(20.8)$ & $5(5.2)$ & 6.5 & $(1.9-21.8)$ & 0.002 \\
\hline \multicolumn{6}{|l|}{ Birth order } \\
\hline $1^{\mathrm{st}}$ & $13(27.1)$ & $28(29.2)$ & 0.9 & $(0.4-1.9)$ & 0.794 \\
\hline$\geq 2^{\text {nd }}$ & $35(72.9)$ & $68(70.8)$ & & & \\
\hline \multicolumn{6}{|l|}{ Birth weight } \\
\hline Normal & $37(77.1)$ & $79(82.3)$ & & & \\
\hline Preterm & $11(22.9)$ & $17(17.7)$ & 1.4 & $(0.6-3.2)$ & 0.457 \\
\hline \multicolumn{6}{|l|}{ Gestational age } \\
\hline Normal & $38(79.2)$ & 87 (90.6) & Ref & & \\
\hline Premature & $9(18.7)$ & $6 \quad(6.3)$ & 3.4 & $(1.1-10.3)$ & 0.028 \\
\hline Post mature & $1 \quad(2.1)$ & $3(3.1)$ & 0.8 & $(0.9-7.6)$ & 0.817 \\
\hline $\begin{array}{l}\text { Maternal age } \\
(\text { mean } \pm S D)\end{array}$ & $29.6 \pm 5.7$ & $31 \pm 5.8$ & & & 0.168 \\
\hline $\begin{array}{l}\text { Paternal age } \\
(\text { mean } \pm S D)\end{array}$ & $35.5 \pm 9.9$ & $36.3 \pm 7.6$ & & & 0.646 \\
\hline $\begin{array}{l}\text { Child's age } \\
(\text { mean } \pm S D)\end{array}$ & $2 \pm 2$ & $1.6 \pm 1.5$ & & & 0.180 \\
\hline
\end{tabular}

Discussion. This retrospective study investigated the association between a number of maternal and paternal risk factors and the development of ARMs. Multivariate analysis concluded that, among the examined factors,

Table 2 - Factors associated with anorectal malformations development in univariate analysis (continued).

\begin{tabular}{|c|c|c|c|c|c|}
\hline Factors & Cases & Controls & OR & $95 \% \mathrm{CI}$ & $P$-value \\
\hline \multicolumn{6}{|c|}{ Chronic disease in mother } \\
\hline Yes & $3(6.3)$ & $9(9.4)$ & 0.6 & $(0.2-2.5)$ & 0.751 \\
\hline No & $45(93.8)$ & $87(90.6)$ & & & \\
\hline \multicolumn{6}{|c|}{ Gestational diabetes } \\
\hline Yes & $2(4.2)$ & $10(10.4)$ & 0.4 & $(0.9-1.9)$ & 0.201 \\
\hline No & $46(95.8)$ & $86(89.6)$ & & & \\
\hline \multicolumn{6}{|c|}{ Anemia } \\
\hline Yes & $23(47.9)$ & $30(31.3)$ & 2 & $(0.9-4.1)$ & 0.051 \\
\hline No & $25(52.1)$ & $66(68.8)$ & & & \\
\hline \multicolumn{6}{|c|}{ Fever $>38^{\circ} c$ during $1^{s t}$ trimester } \\
\hline Yes & $8(16.7)$ & $7 \quad(7.3)$ & 2.5 & $(0.9-7.5)$ & 0.083 \\
\hline No & $40(83.3)$ & $89(92.7)$ & & & \\
\hline \multicolumn{6}{|c|}{ Intake (3 months before) or during pregnancy } \\
\hline \multicolumn{6}{|c|}{ Iron supplements } \\
\hline Yes & $41(85.4)$ & $88(91.7)$ & 0.5 & $(0.9-1.6)$ & 0.247 \\
\hline No & $7(14.6)$ & $8 \quad(8.3)$ & & & \\
\hline \multicolumn{6}{|c|}{ Contraceptive pills } \\
\hline Yes & $15(31.3)$ & $26(27.1)$ & 1.2 & $(0.6-2.6)$ & 0.601 \\
\hline No & $33(68.8)$ & $70(72.9)$ & & & \\
\hline \multicolumn{6}{|c|}{ Folic acid } \\
\hline Yes & $40(38.3)$ & $90(93.8)$ & 0.3 & $(0.1-1)$ & 0.097 \\
\hline No & $8(16.7)$ & $6(6.3)$ & & & \\
\hline \multicolumn{6}{|c|}{ Antibiotics } \\
\hline Yes & $7(14.6)$ & $10(10.4)$ & 1.5 & $(0.5-4.1)$ & 0.465 \\
\hline No & $41(85.4)$ & $86(89.6)$ & & & \\
\hline \multicolumn{6}{|c|}{ Antipsychotic medications } \\
\hline Yes & 0 & $1 \quad(1.0)$ & 1.5 & $(1.3-1.7)$ & 1 \\
\hline No & $48(100)$ & $95(99.0)$ & & & \\
\hline \multicolumn{6}{|c|}{ Cigarette smoking } \\
\hline Yes & $1 \quad(2.1)$ & $2(2.1)$ & 1 & $(0.9-11.3)$ & 1 \\
\hline No & $47(97.9)$ & $94(97.9)$ & & & \\
\hline \multicolumn{6}{|c|}{ Water pipe smoking } \\
\hline Yes & $1 \quad(2.1)$ & $3(3.1)$ & 0.7 & $(0.8-6.5)$ & 1 \\
\hline No & $47(97.9)$ & $93(96.6)$ & & & \\
\hline \multicolumn{6}{|c|}{ Household smoke } \\
\hline Yes & $14(29.2)$ & $24(25.0)$ & 1.2 & $(0.6-2.9)$ & 0.593 \\
\hline No & $34(70.8)$ & $72(75.0)$ & & & \\
\hline \multicolumn{6}{|c|}{ Cigarette smoking of father } \\
\hline Yes & $13(27.1)$ & $27(28.1)$ & 0.9 & $(0.4-2.1)$ & 0.895 \\
\hline No & $35(72.9)$ & $69(71.9)$ & & & \\
\hline \multicolumn{6}{|c|}{ Water pipe smoking of father } \\
\hline Yes & $11(22.9)$ & $20(20.8)$ & 1.1 & $(0.5-2.6)$ & 0.774 \\
\hline No & $37(77.1)$ & $76(79.2)$ & & & \\
\hline
\end{tabular}


Table 3 - Factors associated with anorectal malformations development in multivariate analysis (logistic regression).

\begin{tabular}{|c|c|c|c|c|}
\hline Risk factors & $\mathrm{B}^{*}$ & $\operatorname{Exp}(\mathrm{B})^{\dagger}$ & $\begin{array}{c}95 \% \mathrm{CI} \\
\text { for } \exp (\mathrm{B})\end{array}$ & P-value \\
\hline \multicolumn{5}{|l|}{ Nationality } \\
\hline Non-Saudi & 1.46 & 4.3 & $1.1-17$ & 0.034 \\
\hline Saudi & Ref & Ref & Ref & Ref \\
\hline \multicolumn{5}{|l|}{ Consanguinity } \\
\hline Yes & 0.89 & 2.4 & $1.1-5$ & 0.025 \\
\hline No & Ref & Ref & Ref & Ref \\
\hline \multicolumn{5}{|l|}{ Maternal BMI } \\
\hline Normal & Ref & Ref & Ref & Ref \\
\hline Underweight & 2 & 7.7 & $0.8-77$ & 0.081 \\
\hline Overweight & 0.4 & 1.5 & $0.7-3.4$ & 0.334 \\
\hline Obese & 1.47 & 4.4 & $1.2-15.8$ & 0.025 \\
\hline
\end{tabular}

consanguinity of parents and maternal obesity showed a significant association with the development of ARM. Consanguinity in the local population has been studied and reported as a risk factor for the development of other malformations, and only one study reported on its association with anal atresia. ${ }^{17,18}$ Other factors that have been studied did not seem to be associated with ARM, such age, maternal diabetes, hypertension, gestational diabetes, fever during pregnancy, iron deficiency anemia, intake of contraceptive pills, and folic acid supplementation.

In a Dutch case-control study, it was found that fever during pregnancy and maternal obesity were risk factors. ${ }^{19}$ In another case-control study from 17 European Surveillance of Congenital Anomalies registries for the period between 1980 and 2008, it was found that fever during pregnancy and pre-eclampsia were risk factors for ARM if there were other congenital anomalies present, but not in isolated $A R M .{ }^{20}$ In a population-based case-control study from Sweden involving children with ARM born in the period 1973 to 2014, it was found that maternal obesity (BMI >30), prematurity, and small for gestational age were among the risk factors for ARM. ${ }^{21}$

In a case-control study from Germany involving 158 infants with ARM and 474 healthy infants born between 1993 and 2008, there was a significant association with peri-conceptional maternal smoking and maternal chronic respiratory diseases. ${ }^{22}$ The finding that maternal diabetes is not a risk factor goes with the reported results of some studies and contradicts others. ${ }^{19,21,23}$ In the meta-analysis by Zwink et $\mathrm{al}^{23}$ it included 22 studies investigating the association between smoking, alcohol consumption, caffeine intake, obesity, diabetes, occupational hazards and the development of ARM.
Only paternal smoking and maternal overweight/ obesity and diabetes were found to be risk factors. Furthermore, in another systematic review maternal obesity was a fairly associated risk factor of ARM. ${ }^{24}$

In this study, we could not find any association in specific between paternal smoking (cigarette and water pipe) and ARM. However, other significant finding in this study is that non-Saudi nationality appeared to be a significant risk factor in ARM cases. This may be attributed to expensive maternal care before and during pregnancy or the social and genetic background. Additional studies are suggested to explore why those nationalities are at risk.

Study limitations. One of the limitation is the bias that may occurred in such design. The estimated risk of bias in a case-control study starts with the retrospective pattern, either in the information obtained or in the selection of cases and controls. The information is at risk of recall bias, in which multiple risk factors may be difficult to be recalled by the parents, such as maternal weight before pregnancy, and the expected difference in recalling between the cases and the controls. Another expected bias concerns socially sensitive information, such as maternal smoking of either cigarettes or the water pipe, which may give a low estimate of the real situation. Another limitation was that this study included only available cases in the $\mathrm{MCH}$ hospital; thus, the small sample size. Another limitation arises in the setting, which is restricted to one center rather than being multi-center. Regarding the selection of cases, it was difficult to differentiate syndromic and non-syndromic cases in associated ARM; therefore, we excluded the known chromosome anomalies to restrict the chosen cases as much as possible. The study could not be conducted with isolated ARM alone because of the inadequate number of cases.

This study looked at a huge number of risk factors for ARM development in the local population and found the association between consanguinity and ARM development. Matching the study groups for age and gender added strength to the confounding factors. Choosing community-based relatively healthy children as controls can decrease the bias in selection and reflect the real situation of the selected risk factors.

In conclusion, consanguinity between parents and maternal obesity were found to be associated risk factors for the development of ARM.

Acknowledgment. The authors gratefully acknowledge Prof. Iris A.L.M. van Rooij, Radboud University Medical Center, Netherlands, for providing us the AGORA questionnaire. We also would like to thank Editage (www.editage.com) for the English language editing. 


\section{References}

1. Wood R, Levitt M. Anorectal malformations. Clin Colon Rectal Surg 2018; 31: 61-70.

2. Almaramhy $\mathrm{HH}$. Incidence and spectrum of anorectal malformations in Western Saudi Arabia. Saudi Med J 2012; 33: 1334-1339.

3. Gangopadhyay A, Pandey V. Anorectal malformations. J Indian Assoc Pediatr Surg 2015; 20: 1-10.

4. Zwink N, Jenetzky E, Brenner H. Parental risk factors and anorectal malformations: systematic review and meta-analysis. Orphanet J Rare Dis 2011; 6: 25.

5. Zwink N, Jenetzky E. Maternal drug use and the risk of anorectal malformations: systematic review and meta-analysis. Orphanet J Rare Dis 2018; 13: 75.

6. Alfadhli EM, Osman EN, Basri TH, Mansuri NS, Youssef MH, Assaaedi SA, et al. Gestational diabetes among Saudi women: prevalence, risk factors and pregnancy outcomes. Ann Saudi Med 2015; 35: 222-230.

7. Correa A, Gilboa SM, Besser LM, Botto LD, Moore CA, Hobbs CA, et al. Diabetes mellitus and birth defects. Am J Obstet Gynecol 2008; 199; 237.

8. Borsari L, Malagoli C, Werler MM, Rothman KJ, Malavolti $\mathrm{M}$, Rodolfi R, et al. Joint effect of maternal tobacco smoking and pregestational diabetes on preterm births and congenital anomalies: a population-based study in Northern Italy. $J$ Diabetes Res 2018; 2018: 2782741.

9. Teerlink CC, Bernhisel R, Cannon-Albright LA, Rollins MD. A genealogical assessment of familial clustering of anorectal malformations. J Hum Genet 2018; 63: 1029-1034.

10. Kelsey JL, Whittemore A, Evans AS, Thompson WD. Methods in Observational Epidemiology. 2nd ed. Oxford (UK): Oxford University Press; 1996. p. 432.

11. Aberg A, Westbom L, Källén B. Congenital malformations among infants whose mothers had gestational diabetes or preexisting diabetes. Early Hum Dev 2001; 61: 85-95.

12. van Rooij IALM, van der Zanden LFM, Bongers EMHF, Renkema KY, Wijers CHW, Thonissen M, et al. AGORA, a data- and biobank for birth defects and childhood cancer. Birth Defects Res A Clin Mol Teratol 2016; 106: 675-684.

13. PRAMS Working Group. Pregnancy Risk Assessment Monitoring System (PRAMS), Phase 7 Core QuestionnaireFinal. [Updated 2012; Cited 2018 January 14]. Available from URL: https://www.cdc.gov/prams/pdf/phase-7-corequestions-508.pdf
14. World Health Organization. International respository for information sharing. International statistical classification of diseases and related health problems, 10th revision. 5th ed. [Updated 2017. Cited 2018 January 14]. Available from URL: https://apps.who.int/iris/handle/10665/246208

15. Center for Disease Control and Prevention. National Health Interview Survey. Glossary. [Updated 2017. Cited 2018 January 14]. Available from URL: https://www.cdc.gov/nchs/nhis/ tobacco/tobacco_glossary.htm

16. Maziak W, Ben Taleb Z, Jawad M, Afifi R, Nakkash R, Akl EA, et al. Consensus statement on assessment of water pipe smoking in epidemiological studies. Tob Control 2017; 26: 338-343.

17. Murshid WR. Spina bifida in Saudi Arabia: Is consanguinity among the parents a risk factor? Pediatr Neurosurg 2000; 32: 10-12.

18. Stoll C, Alembik Y, Roth MP, Dott B. Risk factors in congenital anal atresias. Ann Genet 1997; 40: 197-204.

19. Frías JL, Frías JP, Frías PA, Martínez-Frías ML. Infrequently studied congenital anomalies as clues to the diagnosis of maternal diabetes mellitus. Am J Med Genet A 2007; 143A: 2904-2909.

20. Wijers CHW, Van Rooij IALM, Bakker MK, Marcelis CLM, Addor MC, Barisic I, et al. Anorectal malformations and pregnancy-related disorders: A registry-based case-control study in 17 European regions. BJOG 2013; 120: 1066-1074.

21. Svenningsson A, Gunnarsdottir A, Wester T. Maternal risk factors and perinatal characteristics of anorectal malformations. J Pediatr Surg 2018; 53: 2183-2188.

22. Zwink N, Rissmann A, Pötzsch S, Reutter H, Jenetzky E, CURE-Net Consortium. Parental risk factors of anorectal malformations: Analysis with a regional population-based control group. Birth Defects Res A Clin Mol Teratol 2016; 106: 133-141.

23. Åberg A, Westbom L, Kallen B. Congenital malformations among infants whose mothers had gestational diabetes or preexisting diabetes. Early Hum Dev 2001; 61: 85-95.

24. Wijers CHW, van Rooij IALM, Marcelis CLM, Brunner HG, de Blaauw I, Roeleveld N. Genetic and nongenetic etiology of nonsyndromic anorectal malformations: A systematic review. Birth Defects Res C Embryo Today 2014; 102: 382-400. 